\title{
A new mouse model for renal lesions produced by intravenous injection of diphtheria toxin A-chain expression plasmid Shingo Nakamura ${ }^{1,2}$, Masuo Terashima1 ${ }^{1}$ Natsuko Kikuchi ${ }^{3}$, Minoru Kimura ${ }^{3}$, Tadaaki Maehara ${ }^{2}$, Akira Saito ${ }^{1}$ and Masahiro Sato*4
}

Address: ${ }^{1}$ Division of Moleculer Nephrology and Bioartificial Organs, The Institute of Medical Sciences, Tokai University, Bohseidai, Isehara, Kanagawa 259-1193, Japan, ²Department of Surgery II, National Defense Medical College, 3-2 Namiki, Tokorozawa, Saitama 359-8513, Japan, ${ }^{3}$ Division of Molecular Life Science, School of Medicine, Tokai University, Bohseidai, Isehara, Kanagawa 259-1193, Japan and ${ }^{4}$ Department of Molecular Developmental Science, The Institute of Medical Sciences, Tokai University, Bohseidai, Isehara, Kanagawa 259-1193, Japan

Email: Shingo Nakamura - snaka@me.ndmc.ac.jp; Masuo Terashima - Mastera@is.icc.u-tokai.ac.jp; Natsuko Kikuchi - 9jmmd011@is.icc.utokai.ac.jp; Minoru Kimura - kimura@is.icc.u-tokai.ac.jp; Tadaaki Maehara - maehara@gb3.so-net.ne.jp; Akira Saito - asait@is.icc.u-tokai.ac.jp; Masahiro Sato* - masasato@is.icc.u-tokai.ac.jp

* Corresponding author

Published: 22 April 2004

BMC Nephrology 2004, 5:4

This article is available from: http://www.biomedcentral.com/I47I-2369/5/4
Received: 31 October 2003

Accepted: 22 April 2004

(C) 2004 Nakamura et al; licensee BioMed Central Ltd. This is an Open Access article: verbatim copying and redistribution of this article are permitted in all media for any purpose, provided this notice is preserved along with the article's original URL.

\begin{abstract}
Background: Various animal models of renal failure have been produced and used to investigate mechanisms underlying renal disease and develop therapeutic drugs. Most methods available to produce such models appear to involve subtotal nephrectomy or intravenous administration of antibodies raised against basement membrane of glomeruli. In this study, we developed a novel method to produce mouse models of renal failure by intravenous injection of a plasmid carrying a toxic gene such as diphtheria toxin A-chain (DT-A) gene. DT-A is known to kill cells by inhibiting protein synthesis.
\end{abstract}

Methods: An expression plasmid carrying the cytomegalovirus enhancer/chicken $\beta$-actin promoter linked to a DT-A gene was mixed with lipid (FuGENE ${ }^{\mathrm{TM}} 6$ ) and the resulting complexes were intravenously injected into adult male B6C3FI mice every day for up to 6 days. After final injection, the kidneys of these mice were sampled on day 4 and weeks 3 and 5 .

Results: $\mathrm{H}$-E staining of the kidney specimens sampled on day 4 revealed remarkable alterations in glomerular compartments, as exemplified by mesangial cell proliferation and formation of extensive deposits in glomerular basement membrane. At weeks 3 and 5 , gradual recovery of these tissues was observed. These mice exhibited proteinuria and disease resembling sub-acute glomerulonephritis.

Conclusions: Repeated intravenous injections of DT-A expression plasmid DNA/lipid complex caused temporary abnormalities mainly in glomeruli of mouse kidney. The disease in these mice resembles sub-acute glomerulonephritis. These DT-A gene-incorporated mice will be useful as animal models in the fields of nephrology and regenerative medicine. 


\section{Background}

Glomerular injury has been thought to play an important role in progression to renal failure. To search for therapeutic drugs for renal failure, it is of importance to use renal disease models in animals. There are several experimentally-induced models in animals, including subtotal nephrectomized animals, [1,2] snake venom-induced glomerulonephritis models, [3] and glomerulonephritis models produced by tail-vein injection of antiserum [4-7]. Transgenic mice overexpressing megsin, a novel protein of Kunitz-type plasminogen activator inhibitor, under a ubiquitous promoter system CAG [8] (composed of cytomegalovirus enhancer and chicken $\beta$-actin promoter) are reported to exhibit glomerular nephritis associated with mesangial proliferation, accumulation of extracellular matrix and deposits of IgG [9]. Experimentally induced models are always accompanied by fluctuation in degree of manifestation of disease among individuals, and much time (for example, probably over 8 months for subtotal nephrectomy) is often required to produce them. It is often difficult to obtain transgenic animals by the classical pronuclear injection method, [10] and molecular characterization of the introduced gene (genotyping) and its expression must often be performed.

In this study, we intended to produce a new mouse model of renal failure using a simple and convenient method through in vivo introduction of non-viral DNA carrying a toxic gene such a diphtheria toxin A-chain (DT-A) gene. DT-A is known to kill cells by ribosylating the EF2 translation-initiation factor and inhibiting protein synthesis [11]. It is estimated that a single molecule of the natural protein is sufficient to kill a cell [12]. DT-A has been used to selectively ablate tissues and cells in transgenic animals [13-17]. We employed tail-vein-mediated injection of plasmid DNA/lipid complex for kidney-targeted gene transfer, since i) the method itself is non-invasive (it does not require surgical treatment), simple and convenient, and ii) successful gene delivery to the kidney has been reported from several laboratories with this method [1824]. Furthermore, we employed the CAG promoter system to drive DT-A gene expression, since it has been proven to be functional in murine glomeruli, as noted previously [9]. In this study, we consistently observed glomerular dysfunction resembling sub-acute glomerulonephritis after successive intravenous introduction of DT-A expression plasmid DNA/lipid complex. To our knowledge, no other approach using this technique has been tried.

\section{Methods \\ Mice}

B6C3F1 (CLEA Japan, Inc., Tokyo, Japan; a hybrid between $\mathrm{C} 57 \mathrm{BL} / 6 \mathrm{~N}$ and $\mathrm{C} 3 \mathrm{H} / \mathrm{HeN}$ ) male mice, aged 8 to 15 weeks, were used for intravenous injection of plasmid DNA. Adult MNCE-36 transgenic mice (aged 8-15 weeks)
[25] were also used as a control for monitoring CAG promoter specificity in renal tissue. They expressed enhanced green fluorescent protein (EGFP) ubiquitously under control of the CAG promoter [25].

Mice were kept on a $12 \mathrm{~h}$ light/12 h dark schedule (lights on from $0700 \mathrm{~h}$ to $1900 \mathrm{~h}$ ) and allowed food and water ad libitum. Experiments were carried out in accordance with the Guide for the Care and Use of Laboratory Animals at Tokai University. All efforts were made to minimize the number of animals used and their suffering.

\section{Preparation of plasmid vector and DNA/lipid complex}

For expression of DT-A, pCAG/DT-A plasmid DNA (Figure 1A) was used. A 0.6-kb Hin dIII and Bam HI fragment containing a DT-A gene was isolated from pBI106 [26]. This fragment was Klenow-filled and then inserted into the Eco RI site (the site had been destroyed by T4 DNA polymerase treatment) in the 3rd exon of rabbit $\beta$-globin gene in pBsCAG-2, [27] a derivative of pCAGGS [8]. pBsCAG-2 [hereafter referred to as pCAG lacking the DTA gene (Figure 1A)] was used as a negative control. For expression of EGFP, pCE-29 plasmid [28] (Figure 1A) was used. In these three plasmids, the CAG promoter was employed for systemic expression of a downstream cDNA or gene.

All solutions used for intravenous DNA injection were prepared at a volume of $200 \mu \mathrm{l} /$ mouse. Forty $\mu \mathrm{l}$ of FuGENE ${ }^{\mathrm{TM}} 6$ (Boehringer Mannheim GmbH, Mannheim, Germany), a transfection reagent (lipid), was diluted with $60 \mu \mathrm{l}$ of PBS(-), and then added to $20 \mu \mathrm{g}$ of circular plasmid DNA dissolved in $100 \mu$ l of PBS(-) according to the manufacturer's protocol. For control injection (mock injection), a solution containing $40 \mu \mathrm{l}$ of FuGENE ${ }^{\mathrm{TM}} 6$ dissolved in PBS(-) (without DNA) or PBS(-) only was prepared.

\section{Intravenous injection of plasmid DNA/FuGENE ${ }^{\mathrm{TM}} 6$ complex}

Solution containing plasmid DNA/FuGENE ${ }^{\mathrm{TM}} 6$ complex, FuGENE ${ }^{\mathrm{TM}} 6$ only or PBS(-) only was injected into the tail vein of unanesthetized B6C3F1 males with a 1-ml plastic disposable syringe (Terumo, Tokyo, Japan) fitted with a 27-gauge needle (Nipro, Osaka, Japan). Injections were performed at a speed of $200 \mu \mathrm{l} / 8-10 \mathrm{sec}$. This injection was repeated every day for up to 6 days (Figure 1B).

\section{Isolation of tissues and preparation of genomic DNA for polymerase chain reaction (PCR) analysis}

Genomic DNA of organs was isolated as previously described [29] with several modifications [30]. PCR amplification reactions were performed, as previously described [31]. One set of primers (DTA-S and DTA-2RV) for detection of the introduced pCAG/DT-A is listed in 


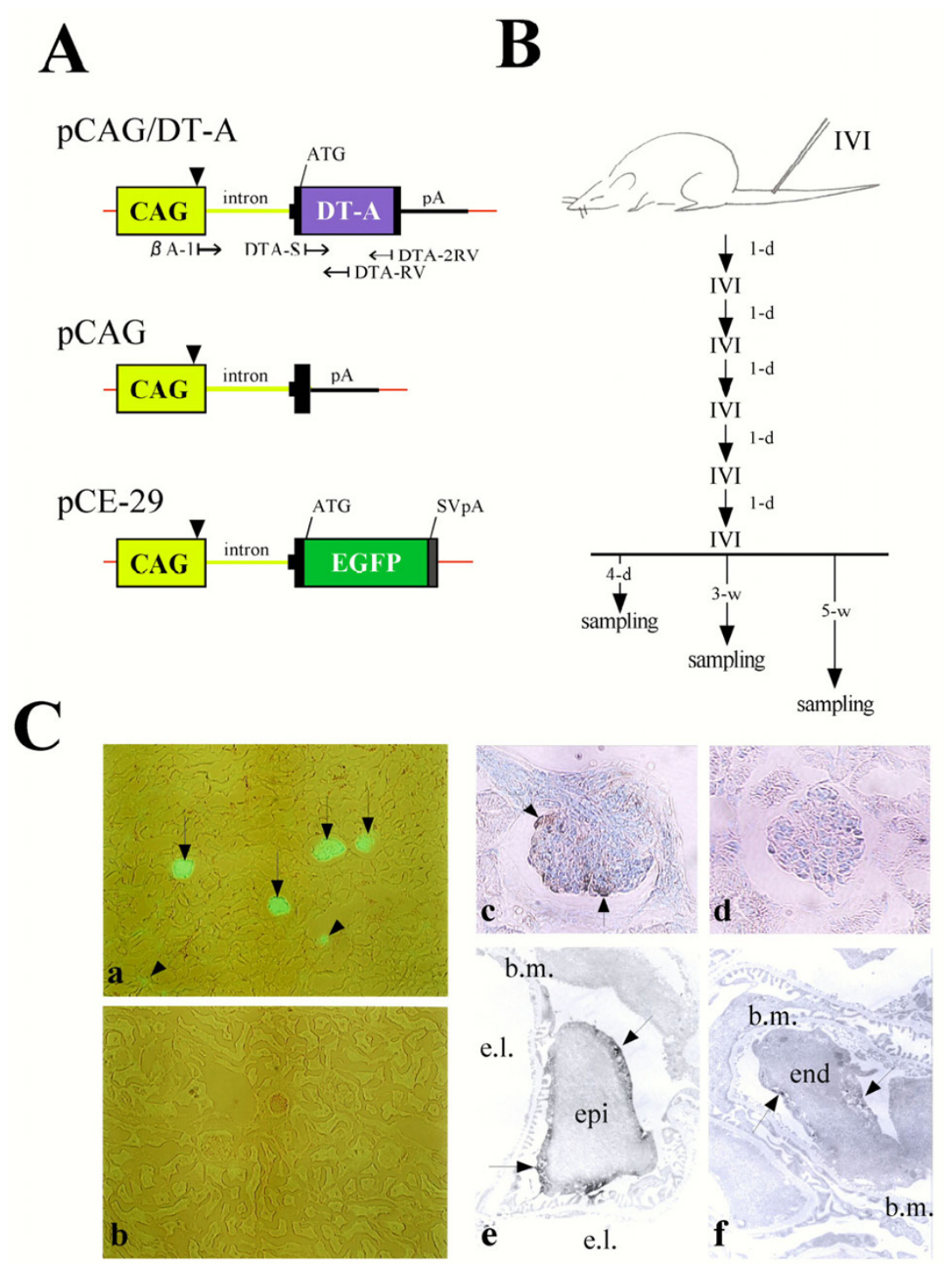

\section{Figure I}

(A) Schematic diagram of the vector constructs PCAG/DT-A, pCAG and pCE-29. Small arrows beneath the pCAG/DT-A plasmid indicate positions and directions of primers used for PCR and RT-PCR. The PCAG/DT-A vector could be identified by PCR using the primer set DTA-S/DTA-2RV. DT-A mRNA synthesized from the CAG promoter can be identified by RT-PCR using the primer set $\beta A$-I/DTA-RV. Arrowheads above the CAG promoter indicate the transcription initiation site. Thick line indicates a sequence corresponding to a portion of the 2 nd intron, 3rd exon and 3'-noncoding region of rabbit $\beta$-globin gene. Red line indicates the sequence of pBluescript SK(-) vector. A portion of the Ist intron of the chicken $\beta$-actin gene is shown by a green line. ATG, translation initiation site; CAG, cytomegalovirus enhancer and chicken $\beta$-actin gene promoter; DT-A, diphtheria toxin A-chain gene; EGFP, enhanced green fluorescent protein cDNA; pA, polyadenylation site of rabbit $\beta$-globin gene; SVpA, polyadenylation sites of SV40 gene. (B) Schematic diagram of the procedure of intravenous injection (IVI) of plasmid DNA/lipid complex and sampling schedule. IVI was performed every day for up to 6 days. Sampling was performed on 4 days (4-d) and $3(3-w)$ and 5 weeks (5-w) after the final IVI. I-d, I day. (C) (a,b) EGFP fluorescence in the kidneys from MNCE-36 transgenic mouse (a) and its non-transgenic littermate (b). Glomeruli [indicated by arrows in (a)] and a portion of renal tubules [indicated by arrowheads in (a)] were positive for EGFP fluorescence in the transgenic mouse, but the non-transgenic mouse did not exhibit fluorescence. (c,d) Immunohistochemical staining of the glomeruli from the MNCE-36 mouse (c) and its nontransgenic littermate (d) using anti-GFP antibodies. The surface of the transgenic glomerulus [indicated by arrows in (c)] appeared to have reacted intensely with the antibodies, while the non-transgenic control glomerulus did not react with the antibodies. (e,f) Immunoelectron microscopic analysis of the MNCE-36 kidney reacted with anti-GFP antibodies. Reactive substances (indicated by arrows) were predominantly observed in glomerular epithelium (epi) (e) and slightly in glomerular endothelium (end) (f). b.m., basement membrane; e.l., endothelial lumen. 
Figure 1A. This primer set yields 267-bp fragments. DTAS (5'-ATG TTG TTG ATT CTT CTA AAT-3') and DTA-2RV (5'-GCG AGA ACC TTC GTC AGT CCT-3') correspond to nucleotides 87 to 107 and 333 to 353 in the DT-A gene sequence, [26] respectively.

\section{Reverse transcriptase (RT)-PCR analysis}

Total RNA was isolated from organs by the method of Chomczynski and Sacchi [32]. RT-PCR was performed using sense primer $\beta \mathrm{A}-1$ (Figure $1 \mathrm{~A}$ ) and reverse primer DTA-RV (Figure 1A), as previously described [33]. $\beta A-1$ (5'-TCT GAC TGA CCG CGT TAC TCC CAC A-3') corresponds to nucleotides $-1,011$ to -987 of the chicken $\beta$ actin gene sequence, [34] and DTA-RV (5'-CAG AGT ATC CCG CAG CGT CGT-3') to nucleotides 254 to 274 in the 5 ' region of the DT-A gene sequence [26]. The primer set ( $\beta$ A-1/DTA-RV) was designed to produce PCR fragments of $300 \mathrm{bp}$. The PCR primer set (m $\beta A-S / m \beta A-R V)$ [33] for detection of mouse $\beta$-actin mRNA was also used.

\section{Renal function}

Urine samples were collected by grasping mice and immediately transferred to urine testing paper (\#1333; Sankyo Medicals Inc., Tokyo, Japan) to evaluate the levels of protein and occult blood semi-quantitatively. Serum was prepared by separation of the coagulated whole blood by cava puncture after urine collection under pentobarbitalinduced anesthesia. Serum concentrations of blood urea nitrogen (BUN), creatinine (CRT), $\mathrm{Na}^{+}, \mathrm{Cl}^{-}$, and $\mathrm{K}^{+}$were measured by an automated analyzer in SRL Lab. Ltd. (Tokyo, Japan).

\section{Histological processing of organs and inspection of fluorescence}

After mice introduced with plasmid DNA/FuGENE ${ }^{\mathrm{TM}} 6$ complex, FuGENE ${ }^{\mathrm{Tm}} 6$ only or PBS(-) only were perfused with $4 \%$ paraformaldehyde (PFA) in PBS(-), major organs (including brain, heart, lung, pancreas, liver, kidney and intestine) were dissected, post-fixed with 4\% PFA in PBS() at $4^{\circ} \mathrm{C}$ for over 10 days except for the kidney, and then subjected to standard histological processing. The kidney was cut into several slices approximately 3-5 mm thickness. Some specimens were subjected to immunohistochemical, immunoelectron microscopic and electron microscopic analyses, as described below. Major organs including the kidney were paraffin-embedded and then stained with hematoxylin-eosin (H-E). Some of these paraffin-embedded specimens were stained with periodic acid-Schiff (PAS), and periodic acid-Schiff-methenamine silver (PAM).

For inspection of EGFP fluorescence, B6C3F1 mice intravenously injected with pCE-29/FuGENE ${ }^{\mathrm{Tm}} 6$ complex, MNCE-36 transgenic mice or their non-transgenic littermates were perfused with 4\% PFA in PBS(-). Organs were dissected from these mice and cut into several pieces approximately 3-5 $\mathrm{mm}$ in thickness. Some of these specimens were immediately subjected to observation for EGFP fluorescence under a fluorescence stereomicroscope (SZX12, Olympus, Tokyo, Japan) with DM505 filters (BP460-490 and BA515IF, Olympus). This allowed us to examine gene expression directly in the intact organ, thereby avoiding potential artifacts that may be introduced during sample preparation for histochemical examination. The other specimens were further fixed with $4 \%$ PFA in PBS(-) at $4^{\circ} \mathrm{C}$ overnight, dehydrated in a sucrose series in PBS(-) and embedded in O.C.T. compound (Tissue-Tek, No. 4583, Miles Scientific, Naperville, IL) for cryostat sectioning. The sections were observed for EGFP fluorescence using a Olympus BX60 microscope under UV illumination. Microphotographs of the specimens were taken using a digital camera (FUJIX HC-300/ OL; Fuji Film, Tokyo, Japan) attached to an Olympus BX60 or SZX12 microscope and printed out using a digital color printer (CP700DSA; Mitsubishi, Tokyo, Japan).

For immunohistochemistry and immunoelectron microscopic analyses, mice were first perfused with 4\% PFA in PBS(-). The kidneys were isolated, sliced and further fixed with $4 \%$ PFA in PBS(-) at $4^{\circ} \mathrm{C}$ for 3 days, treated with $10 \%$ sucrose in PBS(-) at $4^{\circ} \mathrm{C}$ for 3 days, embedded in O.C.T. compound, and frozen at $-80^{\circ} \mathrm{C}$. Sections ( $4 \mu \mathrm{m}$ thick) were cut with a cryostat and subjected to immunohistochemistry using anti-GFP antibodies (\#8367-2; Living Colors A.v. Peptide Polyclonal Antibody, Clontech, MA) and an avidin-biotin coupling (ABC) peroxidase technique performed with the aid of a kit (Vectstain Elite; Vector, Burlingame, CA). The sections were washed in PBS(-) and incubated with $0.02 \%$ diaminobenzidine (DAB) in $0.05 \mathrm{M}$ Tris buffer ( $\mathrm{pH}$ 7.6) containing $0.01 \% \mathrm{H}_{2} \mathrm{O}_{2}$ for 3 min. After washing in PBS(-), the sections were fixed with $2.5 \%$ glutaraldehyde for $3 \mathrm{~min}$ at room temperature. The sections were washed in $\operatorname{PBS}(-)$, post-fixed with $1 \%$ osmium tetroxide in $0.1 \mathrm{M}$ sodium phosphate buffer $(\mathrm{pH}$ 7.4) for $3 \mathrm{~min}$, washed in distilled water, dehydrated in a graded ethanol series, and flat-embedded in Epon 812 (TAAB Laboratories Equipment Ltd., Berkshire, United Kingdom). After polymerization of the Epon 812, we examined the sections by light microscopy, clipped selected fields, and cut them with an ultramicrotome into ultrathin sections, which were then examined for DABstained sites with an electron microscope (JEM-1200EX; JEOL Ltd., Tokyo, Japan).

For electron microscopic analysis, after perfusion with $4 \%$ PFA in PBS(-), the kidneys were isolated, sliced, immersed for $2 \mathrm{~h}$ in $0.1 \mathrm{M}$ sodium phosphate buffer ( $\mathrm{pH} 7.4$ ) containing $2 \%$ glutaraldehyde, post-fixed in $2 \%$ osmium tetroxide in $0.1 \mathrm{M}$ cacodylate buffer for $1 \mathrm{~h}$, dehydrated in acetone, and embedded in Epon 812. Semithin sections 
were stained with toluidine blue and examined by light microscopy to identify regions of the blocks containing several glomeruli. Ultrathin sections were stained with uranyl acetate and lead acetone and were examined with a JEM-1200EX electron microscope.

\section{Glomerular morphometry}

To evaluate the extent of glomerular nephritic lesions, at least 100 glomeruli in $\mathrm{H}$-E-stained sections were randomly chosen per kidney, and lesions were quantified and graded from 0 to 2 : score 0 , normal; score 1 , weak to mild change (exhibiting mild mesangial cell proliferation and mesangial matrix expansion); score 2, severe change (exhibiting lobular structure of glomeruli and adhesion of glomeruli to the inner surface of Bowman's capsule). The extent of glomerular lesions was expressed as a score (\%) using the following formula: The number of glomeruli exhibiting each score/total numbers of glomeruli examined.

\section{Statistical analysis}

All data are means \pm SD $(n=4$ to 6 for each treatment group). For comparison of pairs, statistical analysis the unpaired $t$-test was used with the level of significance set at $P<0.05$.

\section{Results \\ Role of the CAG promoter in kidney-targeted gene expression}

In this study, we used CAG promoter for expression of DTA in mouse kidney, since it has been suggested to be active in murine kidney, particularly glomeruli [9]. Cryostat sections of MNCE-36 kidney revealed bright fluorescence in glomeruli [indicated by arrows in (a) of Figure 1C] and relatively weak fluorescence in some portions of tubules [indicated by arrowheads in (a) of Figure 1C]. Non-transgenic control kidney was completely negative for fluorescence [(b) of Figure 1C]. Other lines, MNCE-39 and -53, [25] exhibited similar distributions of EGFP in kidney (data not shown), eliminating the possibility that the above findings were due to the transgene integration site used. Immunohistochemical staining of cryostat sections revealed that immunoreactive deposits were present on the surface of glomerulus facing Bowman's space [indicated by arrows in (c) of Figure 1C]. Non-transgenic kidney was completely negative for immunoreaction $[(d)$ of Figure 1C]. Immunoelectron microscopic analysis further revealed that immunoreactive deposits were present mainly in glomerular epithelium [indicated by arrows in (e) of Figure 1C] and slightly in glomerular endothelium [indicated by arrows in (f) of Figure 1C]. A portion of mesangial cells was also found to be slightly positive for staining by the antibody (data not shown). Thus, the CAG promoter was concluded to be predominantly active in glomerular epithelial cells.

\section{Determination of optimal transfection parameters}

We used FuGENE ${ }^{\mathrm{TM}} 6$ as reagent for tail-vein-mediated gene delivery to mouse kidney, since it has been proven useful for gene delivery to mid-gestational fetuses after intravenous injection [35]. We performed 6 repeated injections of pCE-29/FuGENE ${ }^{\mathrm{Tm}} 6$ complex for up to 6 days, and examined fluorescence on day 4 . Each treatment yielded deposition of EGFP fluorescence in some organs including the lung, heart, kidney and pancreas. The inner surface of heart (indicated by arrows in Figure 2a), and a portion of inner area (indicated by arrows in Figure 2b) and outer surface (indicated by arrows in Figure 2c), probably endothelial cells, of lung were successfully transfected. This is probably because DNA/lipid complexes have maximal accessibility to these cells upon intravenous injection. In the kidney, EGFP expression was observed in almost all (more than $80 \%$ ) of the glomeruli (indicated by arrows in Figure 2d), although the intensity of staining varied among glomeruli. Expression in kidney declined when inspected on day 7 (data not shown). Other organs (including brain, liver, intestine and spleen) did not fluoresce at a detectable level. Cryostat sectioning of EGFPexpressing kidney confirmed the previous finding that EGFP fluorescence was localized to glomeruli (indicated by arrows in Figures $2 \mathrm{e}, 2 \mathrm{f}$ ) and a portion of renal tubules (indicated by arrowheads in Figure $2 \mathrm{e}$ ), although the distribution and intensity of EGFP fluorescence were more patchy and weaker than in the MNCE kidneys [Figures $2 \mathrm{e}, 2 \mathrm{f} v \mathrm{~s}$. (a) of Figure $1 \mathrm{C}]$. These findings indicated that the overall pattern of EGFP expression in kidney after tailvein-mediated gene transfer was almost the same as that in MNCE transgenic kidney.

Histological examination for renal damage-study on day 4 B6C3F1 male mice were injected 6 times with pCAG/DTA/FuGENE ${ }^{\mathrm{TM}} 6$ complex, pCAG/FuGENE ${ }^{\mathrm{TM}} 6$ complex, FuGENE ${ }^{\mathrm{TM}} 6$ only (mock injection) or PBS(-) only (mock injection). All mice in both experimental and control mock-injected groups appeared healthy during the 6-day gene delivery periods, with the exception that one mouse injected with pCAG/DT-A/lipid complex died suddenly immediately after the final injection. Major organs were immediately dissected from the dead mouse and subjected to molecular biological analysis for detection and expression of pCAG/DT-A. The remaining mice were first subjected to collection of serum and urine, and then perfused with 4\% PFA in PBS(-) prior to isolation of organs and subsequent histological analyses on day 4 and weeks 3 and 5.

H-E staining of the kidneys sampled on day 4 after injection of pCAG/DT-A/FuGENE ${ }^{\mathrm{TM}} 6$ complex revealed remarkable alterations of glomerular components. All specimens ( 8 tested) exhibited similar phenotypic alterations. These alterations included formation of segmental 

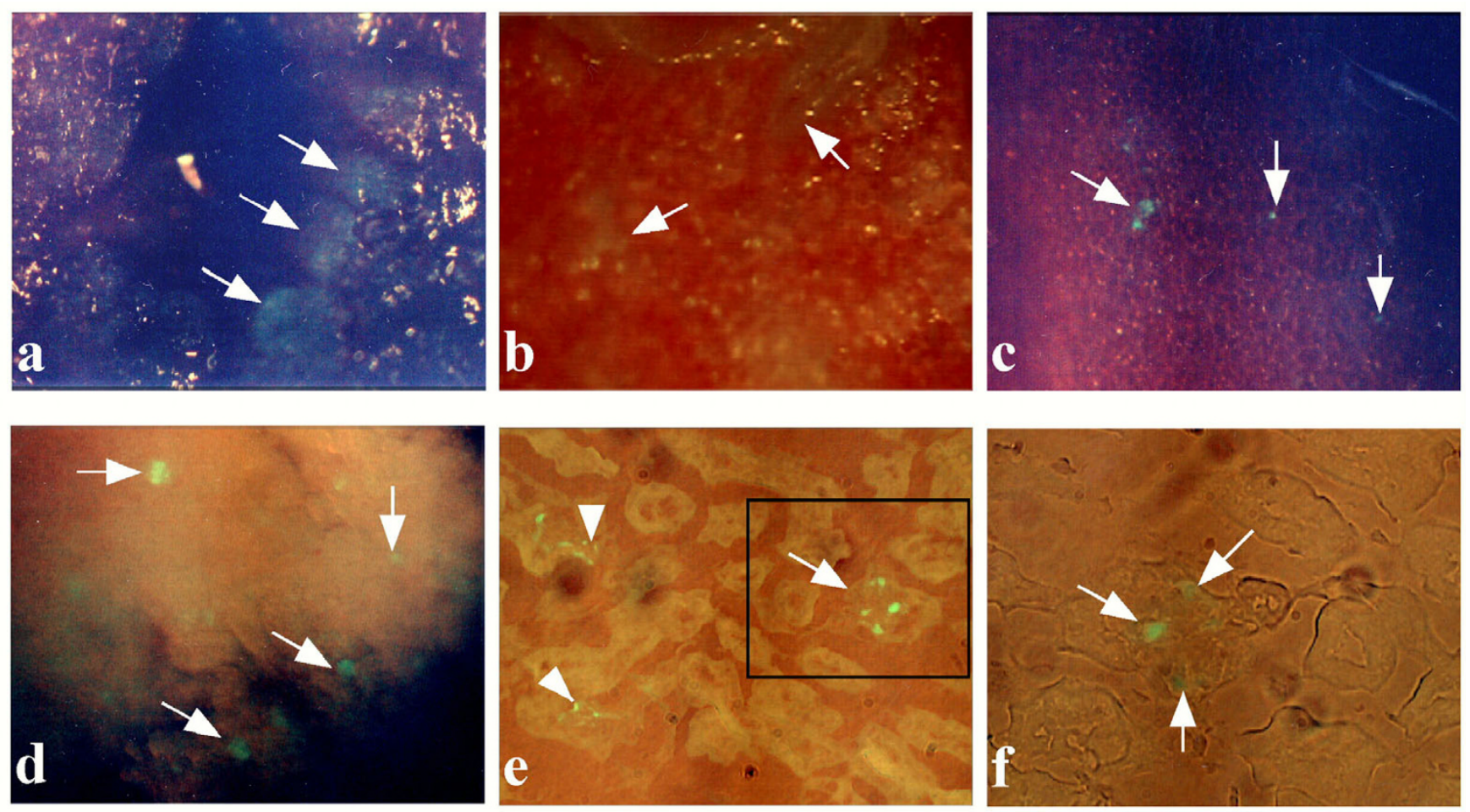

Figure 2

EGFP fluorescence in 4\% paraformaldehyde-fixed heart (a), lung (b,c) and kidneys (d-f) of mice injected 6 times with pCE-29/ FuGENE ${ }^{\mathrm{TM}} 6$ complex. (a) Inner surface of the heart cut into slices. Note that the luminal surface of the heart exhibited focal and slight EGFP fluorescence (indicated by arrows). (b,c) Inner surface (b) of the lung cut into slices and outer (c) surface of the lung. Note focal or patchy expression of EGFP fluorescence in each sample (indicated by arrows). (d) Inner surface of the kidney cut into slices. Note that several glomeruli expressed EGFP fluorescence (indicated by arrows). (e) A cryostat section of the kidney in (d). Patchy expression for EGFP fluorescence (indicated by an arrow) in glomeruli was noted. Also, some renal tubules exhibited faint fluorescence (indicated by arrowheads). (f) A figure magnified from the boxed region in (e). EGFP fluorescence was patchy in the glomerulus (indicated by arrows).

glomeruli (glomerular lobulation) (Figures 3d,3e,3f), mesangial cell proliferation (as evaluated by the presence of mitotic figures in the mesangial region; Figures $3 \mathrm{a}, 3 \mathrm{~d}, 3 \mathrm{e}, 3 \mathrm{f})$, loss of Bowman's space probably due to mesangial cell proliferation (indicated by arrows in Figures $3 a, 3 b$ ), appearance of cellular degeneration (indicated by arrows in Figures 3c,3e), and attenuation of glomerular capillaries (indicated by arrowheads in Figures $3 c, 3 f)$. Notably, inflammatory response (infiltration of mononuclear lymphocytes) in the tubulointerstitium was also observed in some specimens (indicated by arrowheads in Figure 3g). However, none of the mice receiving pCAG/FuGENE ${ }^{\mathrm{TM}} 6$ complex exhibited such glomerular abnormalities (6 kidneys examined; Figure 3j). All mice receiving FuGENE ${ }^{\mathrm{Tm}} 6$ only or PBS(-) exhibited only normal glomeruli (each of 8 kidneys examined; Figure 3k). The kidneys of intact mice were also normal (2 kidneys examined; Figure 31). Inspection of H-E-stained speci- mens revealed no clear abnormality in the other major organs (including brain, heart, lung, pancreas, liver and intestine) tested, although heart, lung and pancreas have previously been identified as susceptible to transfection by exogenous DNA (see Figures $2 \mathrm{a}, 2 \mathrm{~b}, 2 \mathrm{c}$ ).

Electron microscopic analysis of the kidneys (2 kidneys from different mice) treated with pCAG/DT-A/FuGENE ${ }^{\text {TM }} 6$ complex confirmed the above findings. Hypercellularity in the mesangial area of the DT-A expression vectortreated mice was due to increase in number of mesangial cells, accompanied by expansion of matrix (Figure 4a). The most prominent abnormalities observed were formation of focal deposits in glomerular basement membrane (GBM) (indicated by arrows in Figures $4 c, 4 d, 4 e, 4 f)$. Initially, small deposits were also noted in GBM (indicated by arrowheads in Figures $4 \mathrm{~d}, 4 \mathrm{e}$ ). However, other glomerular components including endothelial and epithelial 

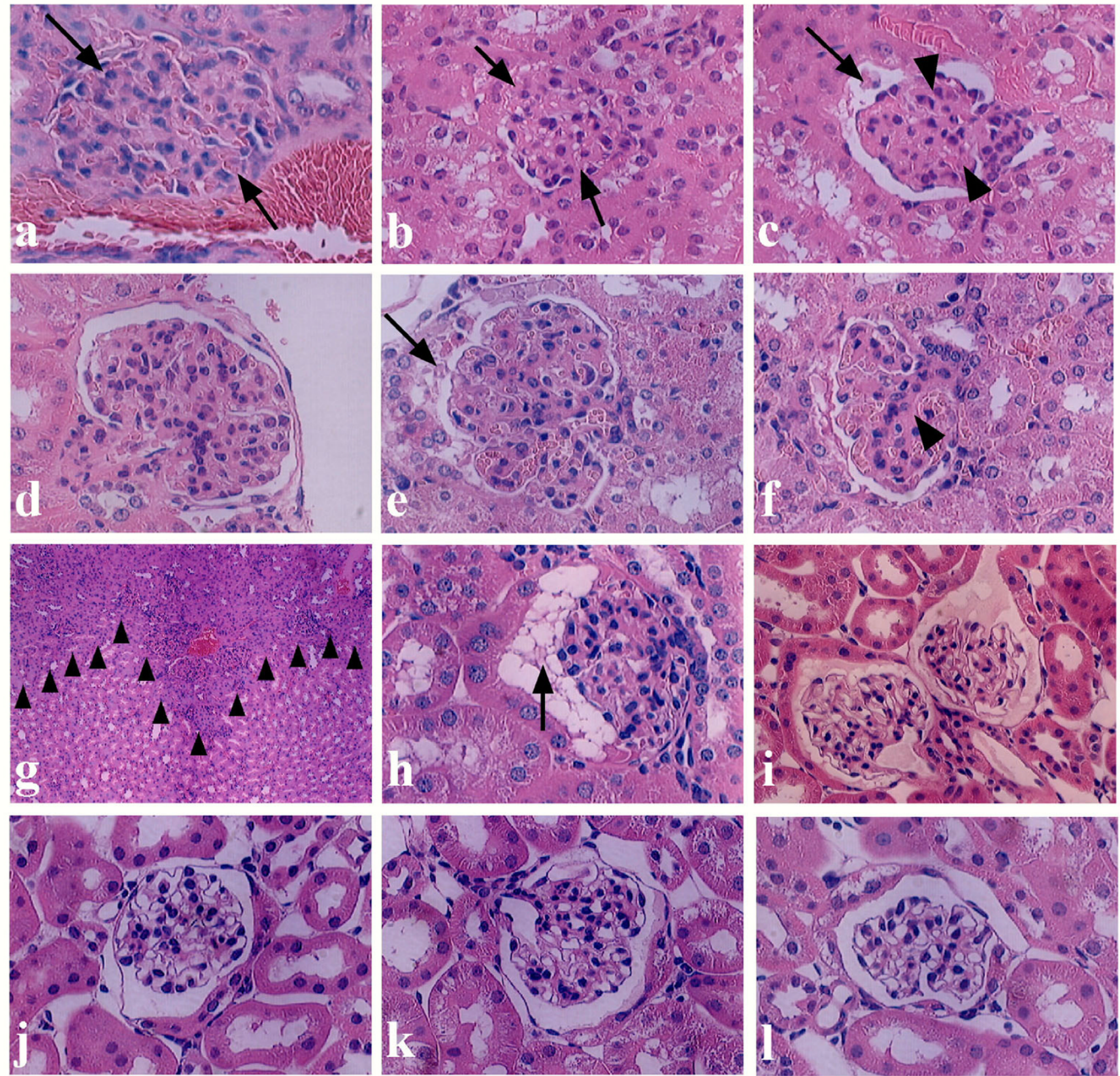

\section{Figure 3}

$\mathrm{H}$-E staining of glomeruli and renal tubules in the kidneys of mice injected 6 times with pCAG/DT-A/FuGENE ${ }^{\text {TM }} 6$ complex (ai), pCAG/FuGENE ${ }^{\mathrm{TM}} 6$ complex (j) or PBS(-) only (k) on day 4 (a-g) and weeks 3 (h) and 5 (i). On day 4, proliferation of mesangial cells, which causes loss of Bowman's space [indicated by arrows in (a) and (b)] and attenuation of glomerular capillaries [indicated by arrowheads in (c)] were remarkable. In some cases, findings of cellular degeneration [indicated by arrows in (c) and (e)] and appearance of lobular segmental structure of glomerulus (d-f) were observed. Infiltration of lymphocytes into interstitum and renal tubules [indicated by arrowheads in $(\mathrm{g})$ ] was sometimes observed. However, no gross alteration in glomeruli was noted in the groups with injection of PCAG/FuGENE ${ }^{\mathrm{TM}} 6$ complex (j) and of mock injections with FuGENE ${ }^{\mathrm{TM}} 6$ only (data not shown) or PBS(-) only (k). On week 3, slight recovery was observed in the mice treated with PCAG/DT-A/FuGENE ${ }^{\mathrm{TM}} 6$ complex, although debris [indicated by an arrow in (h)] existed in Bowman's space. By week 5 , the morphology of glomeruli had almost completely recovered, although proteinaceous substances were often observed in Bowman's space (i). (I), Glomerulus of intact kidney. 

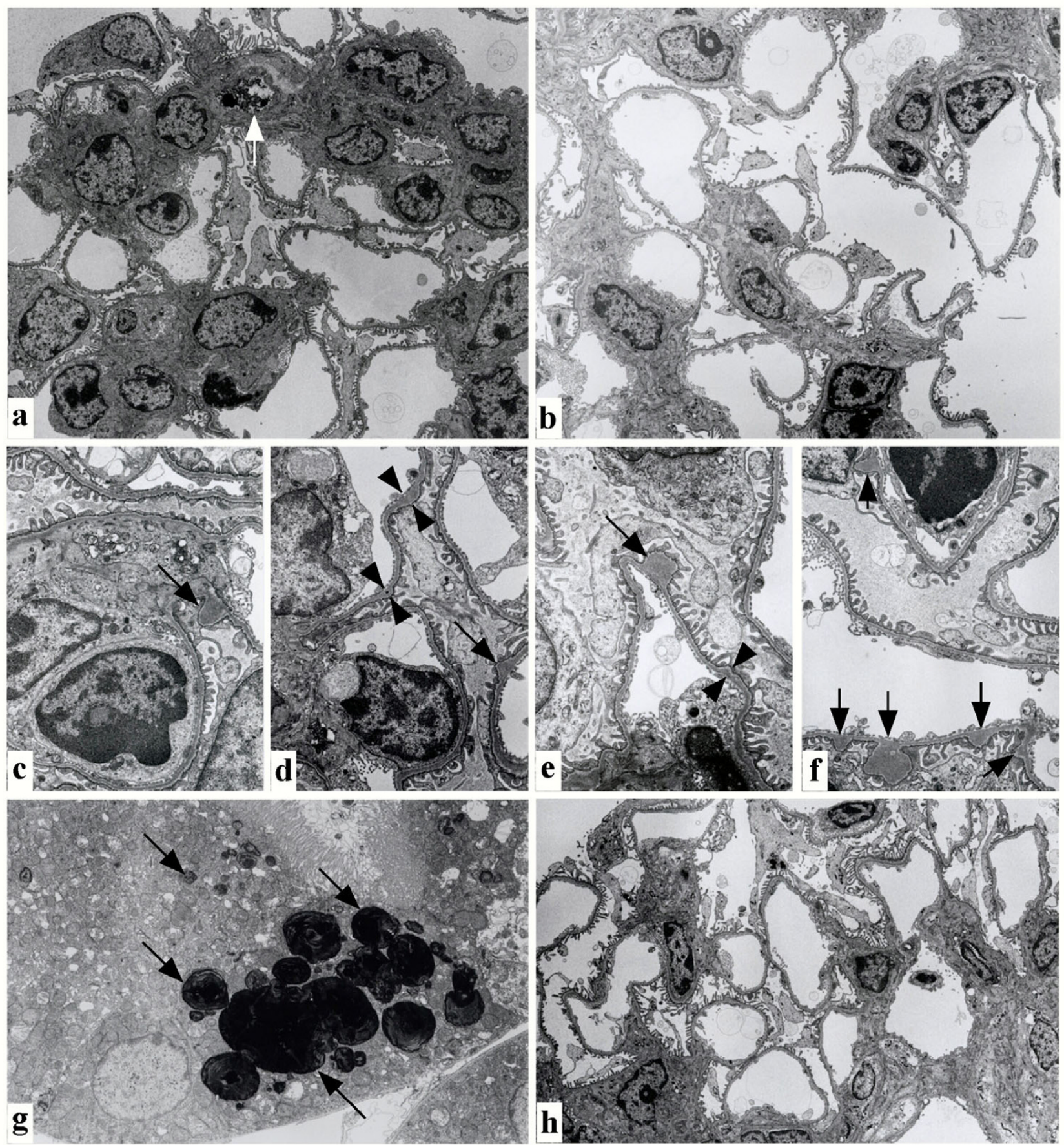

\section{Figure 4}

Electron microscopic analysis of affected glomeruli (a, c-f, h), and tubules ( $g$ ) on day 4 (a, c-g) and week 5 (h) after injection of PCAG/DT-A/FuGENE ${ }^{\mathrm{TM}} 6$ complex. In the affected glomeruli (a), severe matrix expansion with numerous electron-dense deposits was detected in the mesangial matrix. The capillary lumen of endothelial cells was deformed, probably due to proliferation of active mesangial cells. Degeneration of mesangial cells was sometimes observed [indicated by an arrow in (a)]. In contrast, the control glomeruli derived from mock injection of PBS(-) on day 4 (b) exhibited normal appearance. Notably, formation of focal deposits in glomerular basement membrane was often remarkable [indicated by arrows in (c-f)]. The initial, small deposits of glomerular basement membrane are shown by arrowheads in (d) and (e). Incorporation of lipids, probably DNA/lipid complexes that had been re-uptaken by renal tubules, was noted in the cytoplasm of renal tubules [indicated by arrows in (g)]. On week 5, nearly normal glomerular structure was observed $(\mathrm{h})$. 


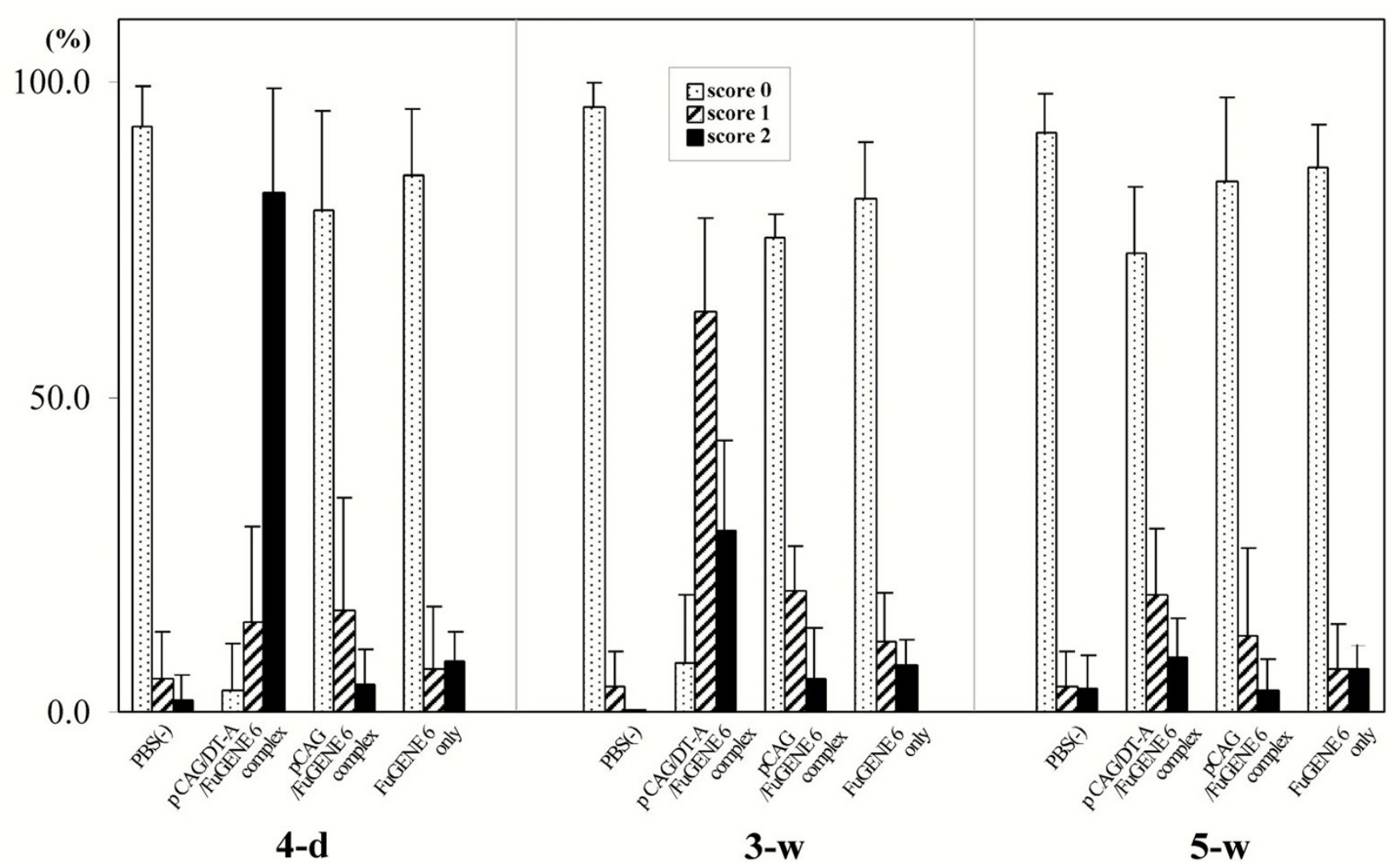

\section{Figure 5}

Glomerular H-E staining scores in the kidney samples on day 4 (4-d) and weeks $3(3-w)$ and 5 (5-w) after repeated injections of PCAG/DT-A/FuGENE ${ }^{\mathrm{TM}} 6$ complex, pCAG/FuGENE ${ }^{\mathrm{TM}} 6$ complex or mock injections [FuGENE ${ }^{\mathrm{TM}} 6$ only or PBS(-) only]. At least 100 glomeruli in the $\mathrm{H}$-E-stained sections were randomly chosen per kidney and the lesions were quantified. A total of 4 kidneys for each group were inspected. The glomerular lesions were graded from 0 to 2: score 0 , normal; score I, weak to mild change (exhibiting mild mesangial cell proliferation and mesangial matrix expansion); score 2, severe change (exhibiting lobular structure of glomeruli and adhesion of glomeruli to the inner surface of Bowman's capsule).

cells appeared almost normal. These cells thus survived without suffering transfection by the DT-A expression plasmid/lipid complex. Degeneration of mesangial cells was sometimes observed (indicated by the arrow in Figure 4a). The control kidney mock-injected with PBS(-) exhibited only normal glomerular structure (2 kidneys from different mice; Figure 4b). These phenotypic alterations were thus thought to have initiated from cellular ablation of glomerular epithelium, glomerular endothelium and some mesangial cells, followed by successive formation of focal deposits in GBM and mesangial cell proliferation. Electron microscopic analysis revealed that the tubules sometimes had electron-dense droplets, probably due to readsorbtion of DNA/lipid complex (indicated by arrows in Figure 4g).
On morphometric analysis of the H-E-stained kidney specimens derived from injection of pCAG/DT-A/ FuGENE ${ }^{\mathrm{TM}} 6$ complex, the percentage of glomeruli scored 2 was approximately $80 \%$ [(4-d) column in Figure 5]. In the kidneys with injection of pCAG/FuGENE ${ }^{\mathrm{Tm}} 6$ complex and those from mock injections, the percentages of glomeruli scored 2 were all below 3\% [(4-d) column in Figure 5]. When the paraffin-embedded specimens derived from the kidney treated with pCAG/DT-A/ FuGENE ${ }^{\mathrm{TM}} 6$ complex were stained for PAS and PAM, there was extensive deposition of PAM-positive materials in the mesangial area (2 kidneys from different mice examined; Figure 6f), indicating expansion of mesangial matrix. The PAS-positive materials did not differ among specimens tested (Figure 6bvs. Figure 6e). 


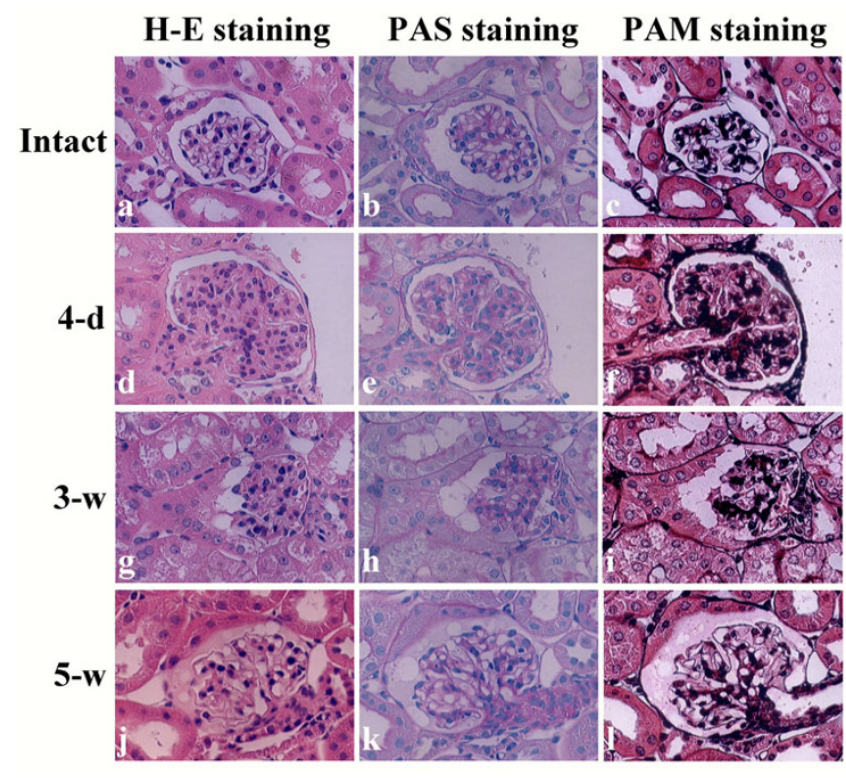

\section{Figure 6}

PAS and PAM staining of kidney sections sampled day 4 (d-f) and weeks $3(g-i)$ and $5(j-l)$ after intravenous administration of pCAG/DT-A/FuGENE ${ }^{\text {TM }} 6$ complex. Note that increased deposition of mesangial matrix, as revealed by increased staining by PAM, was evident in the glomerulus on day $4(f)$, but that in later stages (weeks 3 and 5) such deposits were decreased (i,l). (a-c) indicate intact kidney.

\section{Histological examination for renal damage-study at weeks 3 and 5}

The next step was to evaluate whether the above-mentioned renal lesions would persist over 3 weeks after final administration of a DT-A expression vector.

At week 3, gradual recovery of injured glomeruli was observed in all mice ( 8 kidneys) tested that had been injected with pCAG/DT-A/FuGENE ${ }^{\mathrm{Tm}} 6$. Almost all glomeruli (more than $80 \%$ ) at this stage were scored 1 [(3-w) column in Figure 5]. Notably, a portion of glomeruli was still enriched with proliferated mesangial cells, and cellular debris was often observed in the Bowman's space (indicated by the arrow in Figure $3 \mathrm{~h}$ ). PAS and PAM staining also confirmed the above finding that mesangial deposition was much reduced compared with that in the samples collected on day 4 (2 kidneys from different mice; Figures $6 \mathrm{e}, 6 \mathrm{f} v \mathrm{~s}$. Figures $6 \mathrm{~h}, 6 \mathrm{i}$, respectively).

At week 5, several abnormal findings found in glomeruli sampled at week 3 had nearly been lost: These included expansion of glomerular capillaries and reduction of mesangial cell proliferation and mesangial matrix, although proteinaceous substances were often observed
A
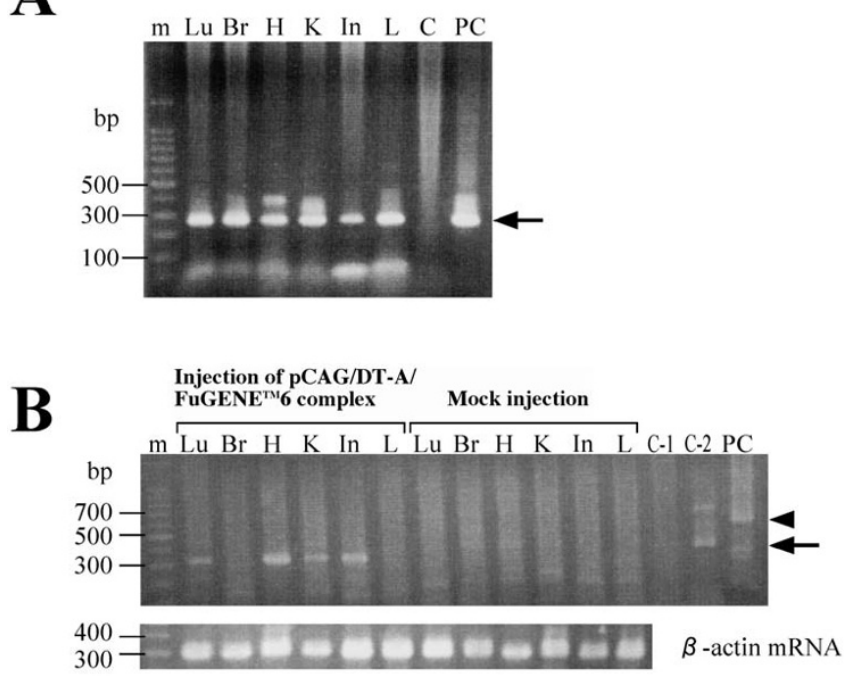

Figure 7

(A) Detection of exogenous PCAG/DT-A by PCR analysis. Genomic DNA was extracted from organs of the mice injected with PCAG/DT-A/FuGENE ${ }^{\mathrm{TM}} 6$ complex or PBS(-) (mock injection). Detection of PCAG/DT-A was performed by PCR using DTA-S/DTA-2RV primer set (see Figure IA). This PCR yielded a product of $267 \mathrm{bp}$ [indicated by an arrow in $(\mathbf{A})$ ]. $C$ indicates that tail DNA (I $\mu \mathrm{g})$ from a B6C3FI mouse was directly subjected to PCR as a negative control. $P C$ indicates that PCAG/DT-A (4 ng) was subjected to PCR as a positive control. (B) Detection of DT-A mRNA by RT$P C R$ analysis. Detection of DT-A mRNA was performed by RT-PCR using $\beta A$-I/DTA-RV primer set (see Figure IA), which yielded an expected band of 300 bp [indicated by an arrow in (B)]. In the lower panel of (B), the expression pattern of endogenous $\beta$-actin mRNA is indicated. Lu, lung; $B r$, brain; $\mathrm{H}$, heart; K, kidney; In, intestine; L, liver. C-I indicates that tail DNA (I $\mu \mathrm{g})$ from a B6C3FI mouse was directly subjected to PCR. C-2 indicates that tail DNA (I $\mu \mathrm{g})$ from a $\mathrm{B} 6 \mathrm{C} 3 \mathrm{FI}$ mouse was directly subjected to reverse transcription and the resulting solution was then PCR-amplified. PC indicates that PCAG/DT-A (4 ng) was subjected to RT-PCR as a positive control. A few non-specifically amplified bands above the 300-bp band were observed in lane C-2, and approximately 600-bp bands [indicated by an arrowhead in (B)], probably corresponding to the products obtained through amplification of PCAG/DT-A, were also seen in lane PC.

in the Bowman's space (Figure 3i). Electron microscopic observation revealed almost complete recovery of the glomeruli (Figure 4h). This was confirmed by morphometric analysis of H-E-stained specimens: Almost all glomeruli (more than 70\%) at this stage were scored 0 [(5w) column in Figure 5]. Staining with PAS and PAM revealed glomerular structures indistinguishable from 
those of normal kidney specimens (Figures 6b,6cus. Figures $6 \mathrm{k}, 6 \mathrm{l}$, respectively).

\section{PCR and RT-PCR analyses for DT-A expression vector and mRNA in major organs}

To obtain evidence that the abnormalities in kidneys mentioned above are in fact caused by introduction and expression of a DT-A expression vector, we performed PCR and RT-PCR analyses. As shown in Figure 7A, the pCAG/DT-A introduced was detected in all major organs tested (including brain, where it is believed to be difficult for exogenous substances in blood to be transferred due to the blood-brain barrier). RT-PCR analysis revealed that several organs (including lung, heart, kidney and intestine) exhibited a band of the expected size (Figure 7B). Organs derived from mock injection [PBS(-) only] were negative for expression of DT-A mRNA (Figure 7B). These findings suggest that the glomerular injuries reported here were actually caused by expression of the DT-A gene.

\section{Renal function after injection of DT-A expression vectorl lipid complex}

Serum levels of CRT, an endogenous marker of renal function, were transiently elevated in the pCAG/DT-A/ FuGENE ${ }^{\mathrm{TM}} 6$ complex-administered mice, with a peak at day 4, while the other biochemical markers including BUN, $\mathrm{Na}^{+}, \mathrm{Cl}^{-}$, and $\mathrm{K}^{+}$were unaltered through day 4 , and at weeks 3 and 5 (Figure 8). Mice treated with pCAG/ FuGENE ${ }^{\mathrm{TM}} 6$ complex, FuGENE ${ }^{\mathrm{TM}} 6$ only or PBS(-) only exhibited no change in serum parameters at any timepoint tested (Figure 8).

Urine levels of proteins were significantly elevated in the mice treated with pCAG/DT-A/FuGENE 6 complex through day 4 and at weeks 3 and 5 (Table 1). Furthermore, urine levels of occult blood were transiently elevated in the pCAG/DT-A/FuGENE 6 complexadministered mice, with a peak at day 4 (Table 1). These findings suggest that the renal damage caused by DT-A expression is correlated well with alterations in biochemical parameters in serum and urine.

\section{Discussion}

In this study we used the CAG promoter for kidney-targeted expression of the DT-A gene. It may be asked why was used for renal cell ablation without a kidney-specific promoter. In many applications, such tissue-specific promoters are often weak relative to stronger but constitutively expressing viral promoters [36]. In contrast, several studies have demonstrated that the CAG promoter produces high levels of gene expression in vivo. [37,38]. However, it is quite possible that tail-vein-mediated gene delivery of pCAG/DT-A would have deleterious effects on a variety of organs or tissues, because of the ubiquitous nature of CAG promoter activity itself. However, we found here that when a CAG-directed EGFP expression vector was introduced intravenously, gene expression was limited to only a few organs such as kidney, heart, lung and pancreas. In kidney, gene expression was confined to glomeruli and a portion of renal tubules (see Figures $2 \mathrm{~d}, 2 \mathrm{e}, 2 \mathrm{f})$. Except for the kidney no histological abnormality was noted in the latter three organs even after repetitive introduction of a DT-A expression vector. Heart, lung and pancreas may thus be more resistant to the toxicity of DTA than kidney. Furthermore, all the treated mice, except one mouse which suddenly died immediately after the final injection, survived healthy through 5 weeks after DNA introduction. We therefore believe that intravenous injection of CAG promoter-directed non-viral DNA confers glomerulus-targeted gene expression.

It may be asked why we employed repeated injections of non-viral DNA for transfection of renal components. To date, various methods to deliver gene constructs to renal cells have been reported, including introduction of plasmid DNA/lipid complex or viral DNA to renal artery [39-43] or introduction of plasmid DNA to renal artery and subsequent in vivo electroporation [44]. All these require surgery and are therefore invasive. On the other hand, successful gene delivery to kidney by single intravenous injection of non-viral DNA/liposome complex has also been described [18-20,23,24]. In our preliminary test, we found that 6 , but not single and 3, successive introductions of DNA/lipid complex resulted in good in vivo transfection efficiency for renal cells.

Notably, EGFP expression in glomeruli and renal tubules after repeated introduction of pCE-29/lipid complex was weaker and sometimes more patchy than in the MNCE-36 transgenic mice carrying pCE-29 element [(a) in Figure $1 \mathrm{Cvs}$. Figures 2e,2f]. Furthermore, expression declined within a week. This mode of transient gene expression suggests that intravenous gene introduction of a DT-A expression vector would cause mild or partial ablation of glomerular compartments and tubules, which may in turn allow proliferation of renal cells, particularly mesangial cells, following cessation or decline of expression of an exogenous gene. This situation appears to contrast to that of snake venom-mediated acute mesangiolysis [3], which is caused by severe injuries of glomerular compartments. Furthermore, DT-A-mediated renal cell ablation appears to be different from the anti-Thy 1.1 model of experimental glomerulonephritis. In this model, acute mesangiolysis is induced by injected anti-thymocyte antibody, and focal segmental mesangial proliferation commences on around 6 days after antibody injection and the altered phenotype persists for about 30 days, which would hamper regeneration of glomeruli themselves [45]. This persistence is probably due to immune complex formed in situ with consecutive complement activation in 


\section{BUN}
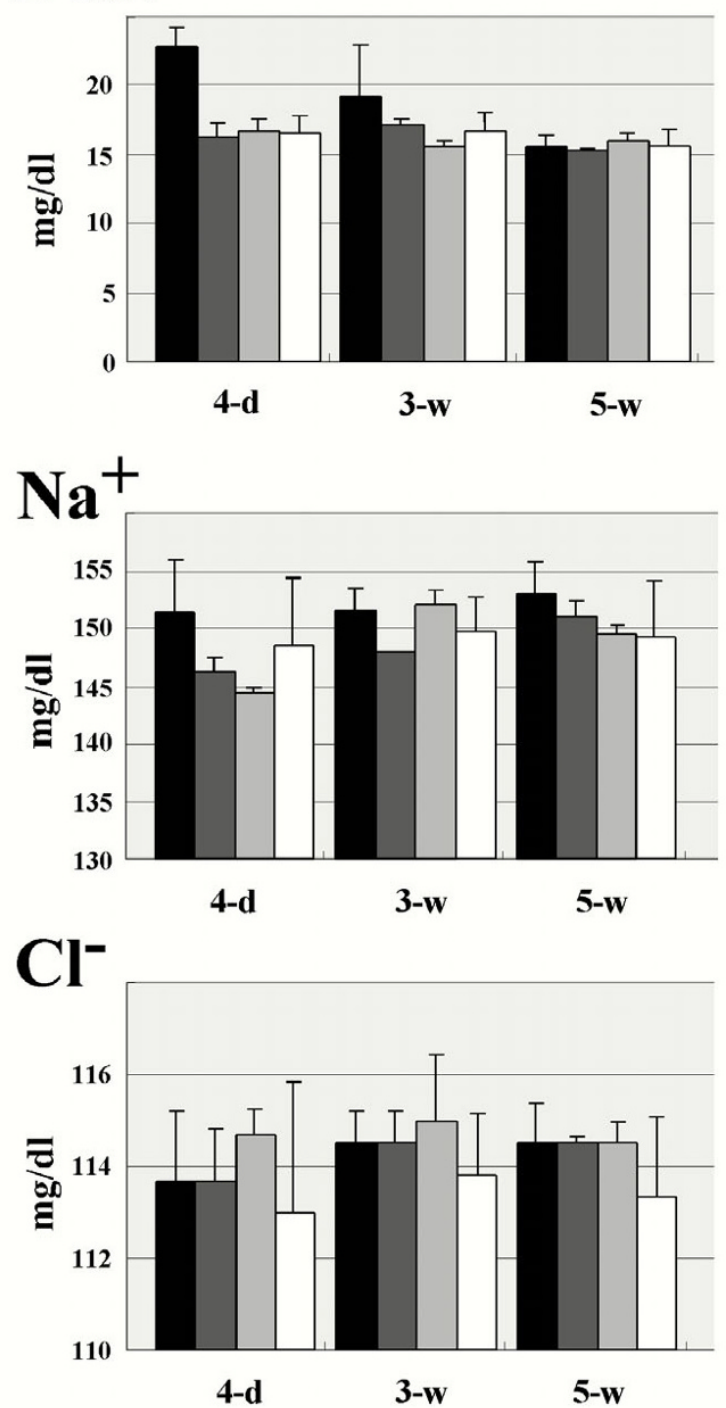

\section{CRT}

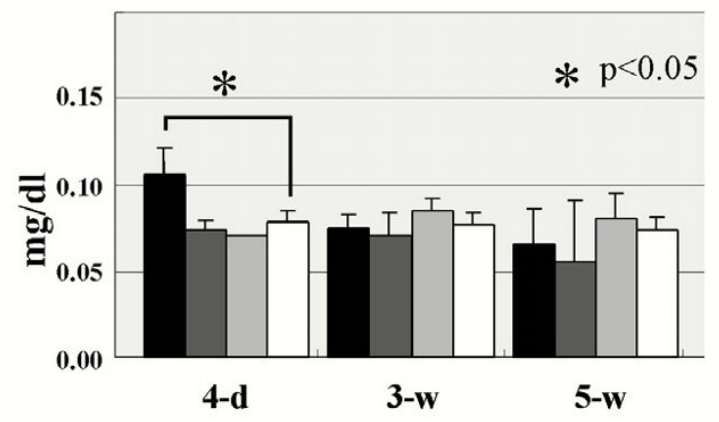

$\mathbf{K}^{+}$

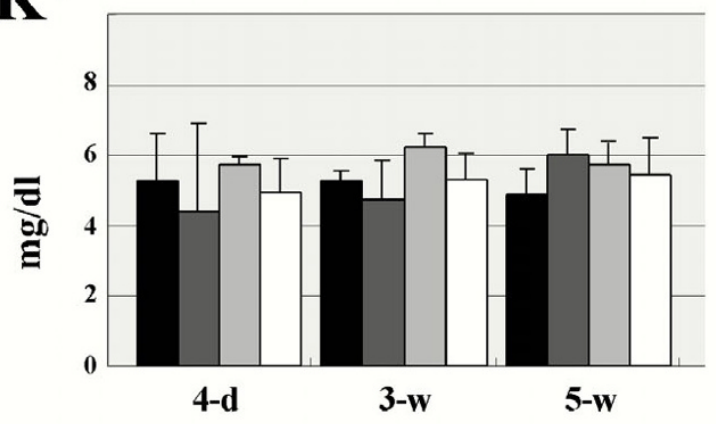

Figure 8

Serum levels of BUN, CRT, $\mathrm{Na}^{+}, \mathrm{K}^{+}$and $\mathrm{Cl}^{-}$in the mice repeatedly injected with pCAG/DT-A/FuGENE ${ }^{\mathrm{TM}} 6$ complex, $\mathrm{pCAG/}$ FuGENE ${ }^{\mathrm{TM}} 6$ complex, FuGENE ${ }^{\mathrm{TM}} 6$ only or PBS(-) only. Serum sampling was performed on day $4(4-d)$ and weeks 3 (3-w) and 5 $(5-w)$.

Table I: Measurement of levels of protein and occult blooda in urine of mice sampled on day 4 and weeks 3 and 5 after 6 repeated administrations of pCAG/DT-A/FuGENE ${ }^{\mathrm{TM}} 6$, pCAG/FuGENE ${ }^{\mathrm{TM}} 6$ complex, FuGENE ${ }^{\mathrm{TM}} 6$ only or PBS(-) only

\begin{tabular}{|c|c|c|c|c|c|c|}
\hline \multirow[t]{2}{*}{ Treatment } & \multicolumn{2}{|c|}{ day 4} & \multicolumn{2}{|c|}{ week 3} & \multicolumn{2}{|c|}{ week 5} \\
\hline & Protein & OCCULT & Protein & OCCULT & Protein & OCCULT \\
\hline PCAG/DT-A/FuGENE ${ }^{\mathrm{TM}} 6$ complex & + & + & + & - & $+/-$ & - \\
\hline pCAG/FuGENE ${ }^{\mathrm{TM}} 6$ complex & - & - & - & - & - & - \\
\hline FuGENE ${ }^{\mathrm{TM}} 6$ only & - & - & - & - & - & - \\
\hline PBS(-) only & - & - & $N D^{b}$ & ND & ND & ND \\
\hline
\end{tabular}

aLevels of protein and occult blood in urine were measured using a urine testing paper. ${ }^{b} N D=$ not determined. 
the mesangium and an overproduction of extracellular matrix components that may contribute to subsequent development of glumerulosclerosis [46].

As observed on electron microscopic analysis, the major defects in glomeruli of the mice treated with DT-A expression vector/lipid complex are focal thickening of GBM and mesangial proliferation. GBM is thought normally to function as a major charge and size barrier to the filtration of macromolecules, and its alteration causes proteinuria [47]. In this context, the existence of a relationship between the deformity of GBM and accelerated protein excretion observed in our mice appears reasonable. On the other hand, on immunoelectron microscopic analysis we observed that the main glomerular compartment targeted by our gene delivery system was glomerular epithelium [see (e) in Figure 1C]. Is glomerular epithelium injury associated with structural alteration in GBM? Hinglais et al. [48] suggest that glomerular epithelial cells are partly responsible for the formation and maintenance of the GBM by synthesizing matrix components. Glomerular cell injuries thus compromise the integrity of the GBM, resulting in loss of its structure and barrier function. If glomerular epithelium and endothelium are the sites where intravenously introduced DT-A expression plasmid is introduced and expressed, it may be asked why electron microscopic analysis failed to demonstrate the presence of degenerated glomerular epithelium and endothelium. In this study, we examined kidneys at 4 days after final introduction of DT-A expression plasmid. By this time, the damaged cells would have been removed from the affected area and immediately replaced by proliferating cells such a mesangial cells.

The mechanism underlying glomerular abnormalities caused by repeated intravenous injections of DT-A expression vector/lipid complex is as follows: i) entrapping of plasmid/lipid complex by glomerular epithelial (and probably endotherial) cells, ii) ablation of glomerular epithelial and endothelial cells due to DT-A expression per se, iii) formation of focal deposits in GBM, leading to elevated levels of urine proteins and occult blood, iv) proliferation of neighboring mesangial cells and expansion of mesangial matrix, which attenuates glomerular capillaries, and v) normalization of mesangial cells, probably due to apoptosis or necrosis of the proliferating mesangial cells themselves. To examine why ablation of glomerular epithelium (and probably endothelium) results in generation of focal deposits in GBM, introduction of a plasmid carrying glomerular epithelium-specific promoterdirected DT-A gene is now being performed.

\section{Conclusions}

Temporary glomerular abnormalities in mice were induced by repeated intravenous injections of DT-A expression vector/lipid complex. These abnormalities resemble sub-acute glomerulonephritis. Mice with these abnormalities will be useful as animal models in the fields of nephrology and regenerative medicine.

\section{Authors' contributions}

SN performed most of the analyses including histopathological and biochemical analyses.

MT provided background on the interpretation of electron microscopic results.

NK performed tail-vein-mediated gene transfer using expression plasmid.

MK supervised the project.

TM supervised the project, and collaborated in the writing of the manuscript.

AS collaborated in the writing of the manuscript, providing background on renal failure.

MS conceived the original concept, performed plasmid construction and molecular biological analysis, and wrote most of the manuscript.

\section{Competing interests}

None declared.

\section{Acknowledgments}

We thank Akira Akatsuka (Teaching and Research Support Center, School of Medicine, Tokai University) for his technical assistance in electron microscopic and immunoelectron microscopic analyses.

\section{References}

I. Brenner BM: Nephron adaptation to renal injury or ablation. Am J Physiol 1985, 249:F324-37.

2. Johnson TS, Griffin M, Thomas GL, Skill J, Cox A, Yang B, Nicholas B, Birckbichler PJ, Muchaneta-Kubara C, Meguid E, Nahas AM: The role of transglutaminase in the rat subtotal nephrectomy model of renal fibrosis. J Clin Invest 1997, 99:2950-60.

3. Morita T, Kihara I, Oite T, Yamamoto T, Suzuki T: Mesangiolysis: Sequential ultrastructural study of habu venom-induced glomerular lesions. Lab Invest 1978, 38:94-102.

4. Shigematsu $\mathrm{H}$ : Glomerular events during the initial phase of rat Masugi nephritis. Virchows Arch B Cell Pathol 1970, 5: 187-200.

5. Mauer SM, Sutherland DER, Howard RJ, Fish AJ, Najarian JS, Michael AF: The glomerular mesangium: III. Acute immune mesangial injury. A new model of glomerulonephritis. J Exp Med I973, 137:553-70.

6. Lowler W: Experimental mesangial proliferation glomerulopathy. J Pathol I98I, I33:107-22.

7. Bagchus WM, Hoedemaeker PJ, Rozing J, Bakker WW: Glomerulonephritis induced by monoclonal anti-Thy $\mathrm{I} . \mathrm{I}$ antibodies. Lab Invest 1986, 55:680-7.

8. Niwa H, Yamamura K, Miyazaki J: Efficient selection for highexpression transfectants with a novel eukaryotic vector. Gene |99|, 108:193-200.

9. Miyata $T$, Inagi $R$, Nangaku M, Imasawa $T$, Sato $M$, Izuhara $Y$, Suzuki $D$, Yoshino A, Onogi H, Kimura M, Sugiyama S, Kurokawa K: Overexpression of the serpin megsin induces progressive mesang- 
ial cell proliferation and expansion. I Clin Invest 2002, 109:585-93.

10. Gordon JW, Scangos GA, Plotkin DJ, Barbosa JA, Ruddle FH: Genetic transformation of mouse embryos by microinjection of purified DNA. Proc Natl Acad Sci USA 1980, 77:7380-7384.

11. Pappenheimer AM: Diphtheria toxin. Annu Rev Biochem 1977, 46:69-94.

12. Yamaizumi M, Mekada E, Uchida T, Okada Y: One molecule of diphtheria toxin fragment $A$ introduced into a cell can kill the cell. Cell 1978, 15:245-50.

13. Palmiter RD, Behringer RP, Quaife CJ, Maxwell F, Maxwell IH, Brinster RL: Cell lineage ablation in transgenic mice by cell-specific expression of a toxin gene. Cell 1987, 50:435-43.

14. Breitman ML, Clapoff S, Rossant J, Tsui LC, Glode LM, Maxwell IH, Bernstein A: Genetic ablation: targeted expression of a toxin gene causes microphthalmia in transgenic mice. Science 1987, 238: $1563-5$.

15. Breitman ML, Bryce DM, Giddens E, Clapoff S, Goring D, Tsui LC, Klintworth GK, Bernstein A: Analysis of lens cell fate and eye morphogenesis in transgenic mice ablated for cells of the lens lineage. Development 1989, 106:457-63.

16. Lowell BB, S-Sisulic V, Hamann A, Lawitts JA, Himms-Hagen J, Boyer $B B$, Kozak LP, Flier JS: Development of obesity in transgenic mice after genetic ablation of brown adipose tissue. Nature 1993, 366:740-2.

17. Herrera PL, Huarte J, Zufferey R, Nichols A, Mermillod B, Philippe J, Muniesa P, Sanvito F, Orci L, Vassalli JD: Ablation of islet endocrine cells by targeted expression of hormone-promoterdriven toxigenes. Proc Natl Acad Sci USA 1994, 91 : 12999-3003.

18. Zhu N, Liggitt $D$, Liu Y, Debs R: Systemic gene expression after intravenous DNA delivery into adult mice. Science 1993, 26 I:209-II.

19. Liu Y, Liggitt D, Zhong W, Tu G, Gaensler K, Debs R: Cationic liposome-mediated intravenous gene delivery. J Biol Chem 1995, 270:24864-70

20. Liu F, Qi H, Huang L, Liu D: Factors controlling the efficiency of cationic lipid-mediated transfection in vivo via intravenous administration. Gene Ther 1997, 4:517-23.

21. Lai LW, Moeckel GW, Lien YH: Kidney-targeted liposome-mediated gene transfer in mice. Gene Ther 1997, 4:426-3I.

22. Lien YH, Lai LW: Liposome-mediated gene transfer into the tubules. Exp Nephrol 1997, 5:132-6.

23. Song YK, Liu F, Chu S, Liu D: Characterization of cationic liposome-mediated gene transfer in vitro by intravenous administration. Hum Gene Ther 1997, 8: I585-94.

24. Oh Y-K, Kim J-P, Yoon JM, Kim JM, Yang J-S, Kim C-K: Prolonged organ retention and safety of plasmid DNA administered in polyethylenimine complexes. Gene Ther 200I, 8:1587-92.

25. Sato M, Watanabe T, Oshida A, Nagashima A, Miyazaki J, Kimura M: Usefulness of double gene construct for rapid identification of transgenic mice exhibiting tissue-specific gene expression. Mol Reprod Dev 200I, 60:446-56.

26. Maxwell IH, Maxwell F, Glode LM: Regulated expression of a diphtheria toxin A-chain gene transfected into human cells: Possible strategy for inducing cancer cell suicide. Cancer Res $1986,46: 4660-4$

27. Kawarabayashi T, Shoji M, Sato M, Sasaki A, Ho L, Echman CB, Prada C-M, Younkin SG, Kobayashi T, Tada N, Matsubara E, lizuka T, Harigaya $Y$, Kasai $K$, Hirai S: Accumulation of $\beta$-amyloid fibrils in pancreas of transgenic mice. Neurobiol Aging 1996, 17:215-22.

28. Sato $M$, Ishikawa A, Kimura M: Direct injection of foreign DNA into mouse testis as a possible in vivo gene transfer system via epididymal spermatozoa. Mol Reprod Dev 2002, 61 :49-56.

29. Blin N, Stafford DW: A general method for isolation of high molecular weight DNA from eukaryotes. Nucleic Acids Res 1976, 3:2303-8.

30. Sato $M$, Iwase $R$, Kasai $K$, Tada N: Direct injection of foreign DNA into mouse testis as a possible alternative of spermmediated gene transfer. Animal Biotechnol 1994, 5:19-3।.

31. Sato $M, K$ asai $K$, Tada N: A sensitive method of testing for transgenic mice using polymerase chain reaction-Southern hybridization. Genetic Anal: Biomol Engin 1995, I 2: I09-II.

32. Chomczynski P, Sacchi N: Single step method of RNA isolation by guanidinium thiocyanate-phenol-chloroform extraction. Anal Biochem 1987, 162:156-9.
33. Sato M, Tada N: Preferential expression of osteocalcin-related protein mRNA in gonadal tissues of male mice. Biochem Biophys Res Commun 1995, 21 5:412-21.

34. Kost TA, Theodorakis N, Hughes $\mathrm{SH}$ : The nucleotide sequence of the chick cytoplasmic $\beta$-actin gene. Nucleic Acids Res 1983, I I:8287-30I.

35. Kikuchi N, Nakamura S, Ohtsuka M, Kimura M, Sato M: Possible mechanism of gene transfer into early to mid-gestational mouse fetuses by tail vein injection. Gene Ther 2002, 9: I529-4I.

36. lyer M, Wu L, Carey M, Wang Y, Smallwood A, Gambhir SS: Twostep transcriptional amplification as a method for imaging reporter gene expression using weak promoters. Proc Nat Acad Sci USA 200I, 98:14595-600.

37. Ishi-i M, Tashiro F, Hagiwara S, Toyonaga T, Hashimoto C, Takei I, Yamamura K, Miyazaki J: Embryonic expression of MHC class heavy and light chains in transgenic mice. Endocr J 1994, 4 I (Suppl):S9-16.

38. Sato M, Kawarabayashi T, Shoji M, Kobayashi T, Hirai S, Tada N: Cytomegalovirus enhancer/chicken $\beta$-actin promoter confers constitutive and ubiquitous transgene expression in vivo. Transgenics 1997, 2:153-9.

39. Bosch RJ, Woolf AS, Fine LG: Gene transfer into the mammalian kidney: Direct retrovirus transduction of regenerating tubular epithelial cells. Exp Nephrol 1993, I:49-54.

40. Moullier P, Friedlander G, Calise D, Ronco P, Perricaudet M, Ferry N: Adenoviral-mediated gene transfer to renal tubular cells in vivo. Kidney Int 1994, 45: 1220-5.

41. Heikkila P, Parpala T, Lukkarinen O, Weber M, Tryggvason K: Adenovirus-mediated gene transfer into kidney glomeruli using an ex vivo and in vivo kidney perfusion system: First steps towards gene therapy of Alport syndrome. Gene Ther 1996, 3:21-7.

42. Zhu G, Nicolson AG, Cowley BD, Rosen S, Sukhatme VP: In vivo adenovirus-mediated gene transfer into normal and cystic rat kidneys. Gene Ther 1996, 3:298-304.

43. Boletta A, Benigni A, Lutz J, Remuzzi G, Soria MR, Monaco L: Nonviral gene delivery to the rat kidney with polyethylenimine. Hum Gene Ther 1997, 8: I243-5I.

44. Tsujie M, Isaka Y, Nakamura H, Imai E, Hori M: Electroporationmediated gene transfer that targets glomeruli. J Am Soc Nephrol 2001, I 2:949-54.

45. Ishizaki M, Masuda $Y$, Fukuda $Y$, Sugisaki $Y$, Yamanaka N, Masugi $Y$ : Experimental mesangioproliferative glomerulonephritis in rats induced by intravenous administration of anti-thymocyte serum. Acta Pathol Jpn 1986, 36: I | 91-203.

46. Floege J, Johnson RJ, Gordon K, lida H, Pritzl P, Yoshimura A, Campbell C, Alpers CE, Couser WG: Increased synthesis of extracellular matrix in mesangial proliferative nephritis. Kidney Int I991, 40:477-88.

47. Kanwar YS, Liu ZZ, Kashihara N, Wallner El: Current status of the structural and functional basis of the glomerular filtration and proteinuria. Semin Nephrol I991, I I:390-4I3.

48. Hinglais N, Kazatchkine MD, Bhakdi S, Appay MD, Mandet C, Grossetete J, Bariety J: Immunohistochemical study of the C5b-9 complex of complement in human kidney. Kidney Int 1986, 30:399-410.

\section{Pre-publication history}

The pre-publication history for this paper can be accessed here:

http://www.biomedcentral.com/1471-2369/5/4/prepub 